\title{
The reaction distance of a planktivorous fish (Scardinius erythrophthalmus) and the evasiveness of its prey (Daphnia pulex $\times$ pulicaria) under different artificial light spectra
}

\author{
Joanna Tałanda ${ }^{1} \cdot$ Piotr Maszczyk $^{1} \cdot$ Ewa Babkiewicz $^{1}$
}

Received: 9 January 2018 / Accepted: 16 May 2018 / Published online: 14 June 2018

(c) The Author(s) 2018

\begin{abstract}
Artificial light at night may affect mortality risk in prey from visually oriented predators because the effect of the artificial light spectrum may differ for a predator's visual prey detection and for prey evasiveness. To test this, we conducted two types of experiment. First, we assessed the reaction distance and swimming speed of juvenile rudd (Scardinius erythrophthalmus) allowed to forage on juvenile Daphnia pulex $\times$ pulicaria under three artificial light sources: halogen, high pressure sodium (HPS), and metal halide bulbs, at the same light intensity. Second, we assessed the evasiveness of $D$. pulex $\times$ pulicaria under the same artificial light sources and in darkness (as a control), in the presence and absence of chemical information on predation risk (kairomones) of juvenile rudd. We found that while both reaction distance and swimming speed of fish was greater under halogen compared to HPS, and similar under metal halide light compared to halogen and HPS, the evasiveness of Daphnia was greater under halogen and HPS-generated light than under metal halide light. The results suggest a possible mismatch of Daphnia's behavioural response under metal halide light to predicted predation risk, and thus a possible threat to predator-prey balance in a lake ecosystem.
\end{abstract}

Keywords Artificial light at night $\cdot$ Evasiveness $\cdot$ Fish kairomones $\cdot$ Predation risk $\cdot$ Swimming speed $\cdot$ Reaction distance

\section{Introduction}

Increasing exposure to artificial light relating to human activity at night is considered a serious threat to organisms today (Hölker et al. 2010). Nocturnal illumination disrupts the natural cycle of light and darkness in various ecosystems, generating a specific type of pollution called ecological light pollution (Longcore and Rich 2004). It has been shown that artificial light at night can alter predator-prey interactions (Gaston et al. 2015; Longcore and Rich 2004; Navara and

Handling Editor: Patrick Fink.

Joanna Tałanda

jtalanda@biol.uw.edu.pl

Piotr Maszczyk

fizbanek@wp.pl

Ewa Babkiewicz

ewa.babkiewicz@wp.pl

1 Department of Hydrobiology, Faculty of Biology, University of Warsaw, Biological and Chemical Research Centre,

Żwirki i Wigury 101, 02-089 Warsaw, Poland
Nelson 2007). For example, many species of bats can efficiently forage at night near artificial light sources that attract insects (Minnaar et al. 2015; Patriarca and Debernardi 2010; Rydell 2006). Although the number of studies on light pollution is increasing from year to year, little is known about aquatic ecosystems, thus they require particular attention (Brüning et al. 2011; Moore et al.2001; Perkin et al. 2011; Perkin et al. 2014).

Numerous studies on predator-prey interactions indicate that the mortality risk of planktonic prey from visually oriented predators, such as planktivorous fish, depends mainly on light intensity (e.g. Utne 1997; Vinyard and O'Brien 1976), and that planktonic prey can assess and respond to this risk. One of the best studied examples of such a response is diel vertical migration (DVM) (Lampert 2011). In the most common (nocturnal) pattern of DVM, zooplankton migrates to warm and food-rich subsurface waters at dusk and returns to deeper waters at dawn to avoid predation risk, mainly from planktivorous fish (Gliwicz 1986; Hutchinson 1967; Ringelberg 1999; Zaret 1980). It has been revealed that descending to the deep dark water layers during the day is the most 
effective mechanism for avoiding predation risk (Greene 1983). However, in the absence of a dark refuge, some other antipredatory strategies can also decrease mortality risk, e.g. the reduction of conspicuousness, swarming and increased evasiveness (Pijanowska et al. 2006; Weber and Van Noordwijk 2002). At high light intensity, the evasiveness of planktonic animals such as Daphnia seems to be the least effective defence, because the probability of being caught by a predator after its attack is between 0.76-0.96 (Drenner 1979). However, in the low light intensity produced by artificial sources near the coastal zone of a lake or ocean, if the reaction distance of fish is low (Utne 1997; Vinyard and O'Brien 1976), the evasiveness of prey could be an effective mechanism for avoiding predation risk.

The literature provides some evidence that zooplankton behaviour is affected not only by light intensity, but also by its spectral characteristics (Smith and Baylor 1953; Storz and Paul 1998). Daphnia have been shown to exhibit positive phototaxis at wavelengths of 569-616 nm, corresponding to a "yellow-orange" colour and that artificial light sources with maximal irradiance in this range are used in light traps to attract pelagic invertebrates (e.g. Ervin and Haines 1972). Artificial light sources emit light with a spectrum that differs from sunlight (Fig. 1). For instance, high pressure sodium lamps (HPS) have the highest spectral irradiance at wavelengths of 569-616 nm, corresponding to a "yellow-orange" colour, while metal halide lamps emit a discontinuous spectrum with many peaks at narrow ranges in different wavelengths.

So far, only Daphnia magna Straus, 1820 (Smith and Macagno 1990) of the cladocerans has had its spectral sensitivity measured. Unlike other crustaceans that are mainly mono- or dichromatic (Marshall et al. 1999), except some stomatopods possessing up to twelve maxima of spectral sensitivity (Marshall and Arikawa 2014), D. magna possesses four classes of photoreceptors with peak sensitivities at 348, 434, 525 and $608 \mathrm{~nm}$ (Smith and Macagno 1990). This means that D. magna is able to perceive UV, but is probably less sensitive to wavelengths corresponding to an "orange-red" colour. Planktivorous fish, in turn, generally possess among 3-4 classes of photoreceptors, these with a maximum absorbance at $620 \mathrm{~nm}$ (Downing et al. 1986; Whitmore and Bowmaker 1989; Bowmaker 1990). Therefore, they are more sensitive to longer wavelengths than Daphnia. Thus, in HPS light, the capture efficiency of these predators could be higher because of their sensitivity to a wider range of wavelengths in comparison to their potential prey, which also possibly is less able to escape in such conditions. On the other hand, if we look at the spectral characteristics of HPS, Daphnia should reveal a stronger response since the maximum absorbance of the photoreceptor at $608 \mathrm{~nm}$ is "closer" to the range of the maximum irradiance of HPS (see Fig. 1) than the fish's $(620 \mathrm{~nm})$.

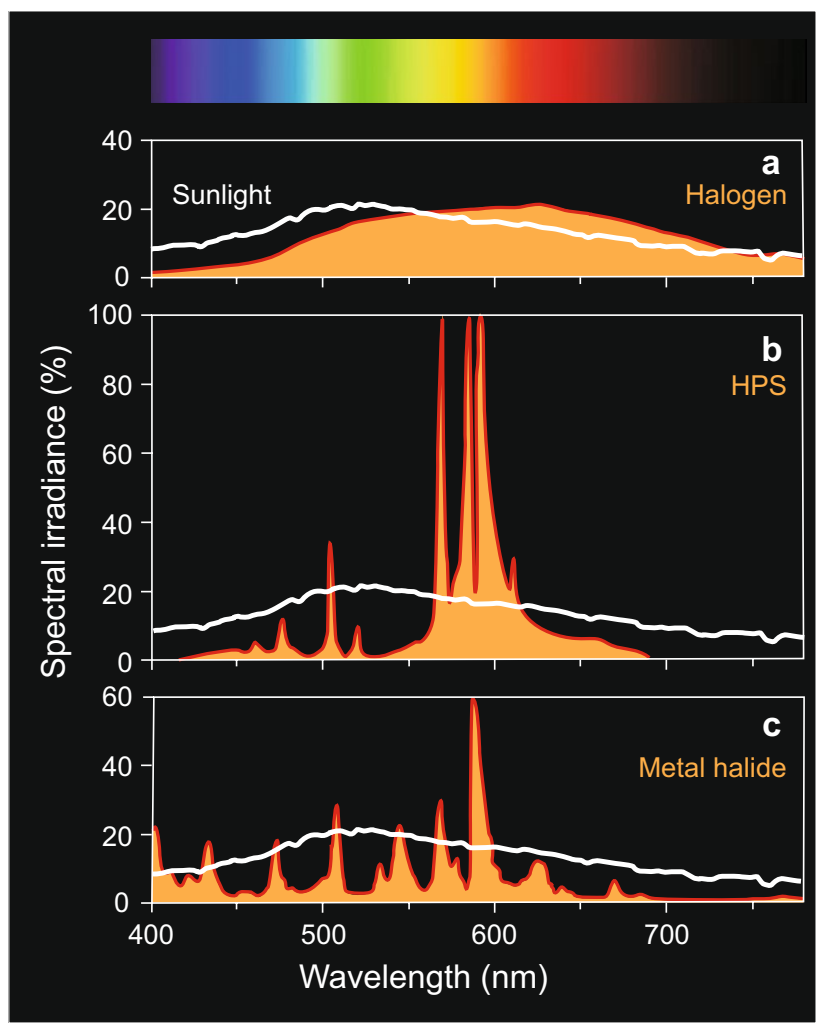

Fig. 1 Spectral irradiance of three artificial light sources used in the experiments: a halogen, b HPS, and $\mathbf{c}$ metal halide, and the spectrum of sunlight (white line) above the water surface in the eutrophic Lake Roś (Great Mazurian Lakes, Poland) measured with a UV-VIS spectrophotometer (USB 4000, Ocean Optics, Dunedin, Florida, USA) and scaled to the HPS spectrum. Note the difference in the continuity of the artificial spectra, with the halogen lamp having a continuous spectrum, and HPS and metal halide with very discontinuous spectra having multiple narrow peaks

Although light is considered the major proximate factor inducing the antipredator response of Daphnia against visually oriented predators, some studies revealed that the presence of a predator's chemical cues (i.e. fish kairomones) strengthens or even determines the reaction to light, because only the simultaneous presence of both signals provides reliable information on predation risk (Brewer et al. 1999; Lass and Spaak 2003; Van Gool and Ringelberg 1995). It has also been shown that in darkness Daphnia generally do not modify their life history and behavioural traits in the presence of kairomones (Effertz and von Elert 2014; Loose et al. 1993; Ślusarczyk et al. 2005).

The aim of our study was to verify the hypothesis that the relative effect of different artificial light sources commonly used in street lighting (halogen, high pressure sodium HPS and metal halide), which produce a similar and low light intensity but with different light spectra (Elvidge et al. 2010), differentiates the ability of a predator (juvenile rudd, Scardinius erythrophthalmus) to visually detect 
prey, and the escape response of its prey, juvenile Daphnia pulex $\times$ pulicaria.

\section{Materials and methods}

\section{The approach}

We performed two experiments to test the hypotheses. The first was designed to assess the reaction distance (RD, as a behavioural proxy for visual prey detection) and swimming speed (SS, as an additional measurement of fish foraging activity) of a planktivorous fish, juvenile Scardinius erythrophthalmus (L., 1758) allowed to forage on juvenile Daphnia pulex $\times$ pulicaria under three artificial light sources: halogen, high pressure sodium (HPS), and metal halide bulbs, which produce the same low light intensity $\left(0.1 \mu \mathrm{mol} \times \mathrm{m}^{-2} \times \mathrm{s}^{-1}\right)$ but have different light spectra. The second experiment was intended to assess the evasiveness of planktonic prey (juvenile Daphnia pulex $\times$ pulicaria) under the same artificial light sources, at the same light intensity and in darkness (as a control), each in the presence and absence of kairomones - chemical cues produced by a predator (juvenile rudd), which can be detected by Daphnia. The light intensity used in the experiments was within the range of the artificial light intensity measured at night $\left(0.13 \pm 0.03 \mu \mathrm{mol} \times \mathrm{m}^{-2} \times \mathrm{s}^{-1}\right), 10 \mathrm{~cm}$ below the surface of a eutrophic lake, Lake Roś (Great Mazurian Lakes, Poland, measurements were taken during a new moon night at 0:00 in April 2016). The tested light intensity $\left(0.1 \mu \mathrm{mol} \times \mathrm{m}^{-2} \times \mathrm{s}^{-1}\right)$ was far above the probable photopic/scotopic threshold of rudd and Daphnia (examples of scotopic thresholds for fish: Hollbach et al. 2015; Ishibashi et al. 2009; light sensitivity of Daphnia: Moore et al. 2006).

\section{Animals}

Juvenile (1+, length $55 \pm 5 \mathrm{~mm}$ ) rudd (Scardinius erythrophthalmus), hatchery grown at the Pond Fishery Department (Żabieniec, Poland), were used as a species that efficiently preys upon zooplankton. We used diurnal fish, as it is predicted that diurnal (visual) predators may prolong foraging time due to artificial light at night. This situation is called "night light niche" (Longcore and Rich 2004). Fish were fed daily with small amounts of frozen Chironomidae larvae and live Daphnia, except for $24 \mathrm{~h}$ before the experiments. During the experiments, 1-day old Daphnia pulex $\times$ pulicaria (body size $0.58 \pm 0.18 \mathrm{~mm}$ ) were offered to the fish. In each experiment, a cohort of prey individuals was produced by females from long established laboratory cultures of one clone originating from a city pond in Warsaw, Poland. They had been maintained in 4-1 jars with aged (14 days) and 2.0- $\mu \mathrm{m}$ filtered lake water, and fed daily with the algae Acutodesmus obliquus (Turpin) Hegewald \& Hanagata, 2000 at a concentration above the incipient limiting food level $\left(1.0 \mathrm{mg} \mathrm{C}_{\text {org }} \times 1^{-1}\right)$. Daphnia females were kept at a water temperature of $21^{\circ} \mathrm{C}$ and a 16:8 L:D photoperiod provided by halogen lamps $\left(35 \mathrm{~W}\right.$, OSRAM $\left.{ }^{\circledR}\right)$ with an intensity of light of $5.5 \mu \mathrm{mol} \times \mathrm{m}^{-2} \times \mathrm{s}^{-1}$. Before each experiment, fish were kept in 6-1 home aquaria (two fish per aquarium) placed in the same air-conditioned laboratory room as the experimental set-up, at a constant water temperature of $21.0^{\circ} \mathrm{C}( \pm 0.1)$ and a daily cycle of 16:8 L:D. Before each experimental day, fish were acclimated to a given spectrum of light by $10 \mathrm{~h}$ at an intensity of $0.5 \mu \mathrm{mol} \times \mathrm{m}^{-2} \times \mathrm{s}^{-1}$. The long acclimation to the tested light spectrum before the experiment was done to lower the stress of the fish and enabled us to obtain precise results for reaction distance and swimming speed. In each trial, a pair of fish was used, since it is known that using more than one fish ensures that they are bolder (Bartosiewicz and Gliwicz 2011).

The experiments on the evasiveness of Daphnia were performed using the same clone of Daphnia pulex $\times$ pulicaria cultured in the same conditions. Kairomones used in these experiments came from rudd used in the aquarium experiments.

Due to the need to use a great number of Daphnia in the experiments (approximately 1000 ind. per day), we used juveniles (instead of adults), which were easier to obtain in a shorter time period. It has been demonstrated that juveniles also clearly respond either to light cues (Pijanowska et al. 2006) and fish kairomones (Maszczyk and Bartosiewicz 2012).

\section{Light sources}

Both types of experiment were carried out using the same light bulbs: halogen $\left(120 \mathrm{~W}\right.$, ANS-Lighting $\left.{ }^{\circledR}\right)$, high pressure sodium $\left(70 \mathrm{~W}\right.$, OSRAM $\left.{ }^{\circledR}\right)$ and metal halide $(70 \mathrm{~W}$, OSRAM $^{\circledR}$ ). The intensity of light for all light sources was equal to $0.1 \mu \mathrm{mol} \times \mathrm{m}^{-2} \times \mathrm{s}^{-1}$ measured with a Li-Cor 189 quantum sensor measuring radiance (Li-Cor Biosciences ${ }^{\circledR}$ ) under the water surface and achieved using obscuring Lee Filters ${ }^{\circledR}$ (measurements in lux: halogen 5.4 1x; HPS $8.2 \mathrm{~lx}$; metal halide $7.1 \mathrm{~lx}$ ). Experiments on the evasiveness of Daphnia in full darkness were carried out using a night-vision device (Pulsar Edge GS $1 \times 20$ Night Vision Binocular).

\section{The experiment on the reaction distance and swimming speed of rudd}

\section{The experimental system}

All of the replicates for the RD and SS of fish were performed in a set-up which allowed both direct observations 
and video recording of the feeding behaviour of planktivorous fish at a constant prey density (described in detail by Gliwicz et al. 2017). The system consisted of a main 80-1 aquarium $(80 \times 67 \times 15 \mathrm{~cm}$, length, height and width, respectively), in which the foraging rudd were observed and video recorded, and an annex aquarium $(30 \times 60 \times 15 \mathrm{~cm})$, in which the fish were placed before the experiment (Gliwicz et al. 2017: 4, Fig. 1). The system was separated from the observers and the camera by a curtain made of black fabric, with rectangular peep-holes. White lines marked off a grid on the black back wall of the aquarium (2-cm squares) to track fish during each experiment. Each light source shone from an elevation of $1 \mathrm{~m}$ through an obscuring Lee filter and semitransparent Plexiglas diffusion plate into the middle of the main aquarium, providing a similar light intensity throughout the entire aquarium, confirmed by readings taken at a 30-cm depth by a UV-VIS spectrophotometer (USB 4000, Ocean Optics, Dunedin, Florida, USA). The video filming was made with a colour TS-6031PSC camera, able to record in low light intensity. The camera was connected to a computer and supported by the Ulead Video Studio 11 program.

\section{Experimental procedures}

During each experimental day we performed 4 experiments (replicates) in one of the three light treatments. Replicates were carried out from 4 to 9 p.m. $\left(10^{\text {th }}\right.$ to the $15^{\text {th }}$ hour of daylight). In each replicate, a pair of fish was observed by two researchers. In total, we used 8 fish (4 pairs) that were observed in all light treatments twice (Table 1).

Prior to each replicate, a pair of fish was transferred into the main aquarium and after $10 \mathrm{~min}$, relocated into the annex to be locked behind the gate (where the fish were acclimated for the next $15 \mathrm{~min}$ at a water temperature of $21^{\circ} \mathrm{C}$ ). At the same time, an initial portion of 80 Daphnia (density of 1 ind. $\times 1^{-1}$ ) was added to the main aquarium. At the beginning of the experiment, the video recording was started, and fish were released into the main tank and allowed to forage for $5 \mathrm{~min}$. The initial density was maintained during the experiment by adding a new portion of 10 prey individuals as soon as 10 had been captured by the two experimental fish. This procedure required two observers to jointly count the captures, each observer following one of the two fish until the total sum of captures was 10 . Then, a new portion of 10 prey individuals was released into the aquarium through a dispenser. Next, the experimental light was switched off, fish were transferred to their home aquarium and the video recording was stopped. As soon as the fish had been transferred back into their home aquarium, water with the uneaten prey was drained through a plankton net suspended inside a barrel below the aquarium. The main aquarium was additionally rinsed with several litres of water, and the water was drained again through the plankton net.
Table 1 The timetable of experiments on the reaction distance and swimming speed of rudd Scardinius erythrophthalmus

\begin{tabular}{|c|c|c|}
\hline Day & Light treatment & Pair of fish \\
\hline \multirow[t]{4}{*}{1} & Halogen & 1 \\
\hline & & 2 \\
\hline & & 3 \\
\hline & & 4 \\
\hline \multirow[t]{4}{*}{2} & HPS & 4 \\
\hline & & 3 \\
\hline & & 2 \\
\hline & & 1 \\
\hline \multirow[t]{4}{*}{3} & Metal halide & 1 \\
\hline & & 2 \\
\hline & & 3 \\
\hline & & 4 \\
\hline \multirow[t]{4}{*}{4} & HPS & 1 \\
\hline & & 2 \\
\hline & & 3 \\
\hline & & 4 \\
\hline \multirow[t]{4}{*}{5} & Metal halide & 4 \\
\hline & & 3 \\
\hline & & 2 \\
\hline & & 1 \\
\hline \multirow[t]{4}{*}{6} & Halogen & 1 \\
\hline & & 2 \\
\hline & & 3 \\
\hline & & 4 \\
\hline
\end{tabular}

The reaction distance (RD) of a foraging fish was measured from the point where it saw a prey and turned to view it with both eyes, to the point where the prey was captured. The reaction distance was measured by studying the video recordings of the trajectories of an individual fish visualized against the grid on the black wall of the aquarium using VirtualDub 1.10.4 free software (see http://www.virtualdub .org/), which allows a precise frame-by-frame analysis of the video to be performed. Examples of captures occurring near the corners, bottom of the aquarium, at the water's surface or in a plane not perpendicular to the observers, and examples of captures located along one, often long line, without an apparent change in the swimming direction of the fish, were not included in the estimations of RD. Swimming speed was measured from the archived video recordings as the distance between two points in a given time between subsequent captures, using VirtualDub 1.10.4 free software.

\section{The experiment on the evasiveness of Daphnia}

The experiment to assess the evasiveness of Daphnia was carried out in a $2 \times 4$ factorial design that included a fishconditioned and non-fish-conditioned water medium, in the 
presence of one of the three artificial light sources or in darkness as a control.

In total, 24 replicates were performed during 4 consecutive days. Each day, 6 replicates ( 3 in the presence and 3 in the absence of kairomones) were carried out in random order under a single light source or in the dark. Each replicate (in the presence and absence of kairomones) in the dark or in the presence of light was performed at the same time by two experimenters (Table 2).

Ten litres of ADaM, an artificial freshwater medium for culturing zooplankton (Klüttgen et al. 1994) was prepared before each experimental day, divided equally into two containers, and kept at a water temperature of $21^{\circ} \mathrm{C}$ (the same as the experimental conditions). Fish-conditioned medium with chemical information on fish presence (kairomones) was obtained by keeping a single rudd in 51 of aerated $\mathrm{ADaM}$ for $24 \mathrm{~h}$ before each experimental day. At the same time, 51 of medium without a fish were also aerated.

Replicates were carried out from 4 to 9 p.m. $\left(10^{\text {th }}\right.$ to the $15^{\text {th }}$ hour of daylight in Daphnia culture). The experimental procedure was consistent with the method proposed by

Table 2 The timetable of experiments on the evasiveness of the cladoceran Daphnia pule $\times$ pulicaria in the presence $(+)$ and absence $(0)$ of kairomones. Experimenters Ewa (E) and Joanna (J)

\begin{tabular}{|c|c|c|c|c|c|}
\hline Day & $\begin{array}{l}\text { No. of } \\
\text { experi- } \\
\text { ment }\end{array}$ & $\begin{array}{l}\text { Light treat- } \\
\text { ment }\end{array}$ & $\begin{array}{l}\text { Replicate } \\
\text { of treat- } \\
\text { ment }\end{array}$ & Kairomone & $\begin{array}{l}\text { Experi- } \\
\text { menter }\end{array}$ \\
\hline \multirow[t]{3}{*}{1} & 1 & $\begin{array}{l}\text { Metal } \\
\text { halide }\end{array}$ & 1 & $\begin{array}{l}+ \\
0\end{array}$ & $\begin{array}{l}E \\
J\end{array}$ \\
\hline & 2 & HPS & 1 & $\begin{array}{l}+ \\
0\end{array}$ & $\begin{array}{l}\mathrm{J} \\
\mathrm{E}\end{array}$ \\
\hline & 3 & Dark & 1 & $\begin{array}{l}+ \\
0\end{array}$ & $\begin{array}{l}\mathrm{E} \\
\mathrm{J}\end{array}$ \\
\hline \multirow[t]{3}{*}{2} & 1 & HPS & 2 & $\begin{array}{l}+ \\
0\end{array}$ & $\begin{array}{l}\mathrm{J} \\
\mathrm{E}\end{array}$ \\
\hline & 2 & Halogen & 1 & $\begin{array}{l}+ \\
0\end{array}$ & $\begin{array}{l}\mathrm{E} \\
\mathrm{J}\end{array}$ \\
\hline & 3 & $\begin{array}{l}\text { Metal } \\
\text { halide }\end{array}$ & 2 & $\begin{array}{l}+ \\
0\end{array}$ & $\begin{array}{l}J \\
E\end{array}$ \\
\hline \multirow[t]{3}{*}{3} & 1 & Dark & 2 & $\begin{array}{l}+ \\
0\end{array}$ & $\begin{array}{l}\mathrm{E} \\
\mathrm{J}\end{array}$ \\
\hline & 2 & Halogen & 2 & $\begin{array}{l}+ \\
0\end{array}$ & $\begin{array}{l}J \\
E\end{array}$ \\
\hline & 3 & HPS & 3 & $\begin{array}{l}+ \\
0\end{array}$ & $\begin{array}{l}\mathrm{E} \\
\mathrm{J}\end{array}$ \\
\hline \multirow[t]{3}{*}{4} & 1 & Halogen & 3 & $\begin{array}{l}+ \\
0\end{array}$ & $\begin{array}{l}\mathrm{J} \\
\mathrm{E}\end{array}$ \\
\hline & 2 & $\begin{array}{l}\text { Metal } \\
\text { halide }\end{array}$ & 3 & $\begin{array}{l}+ \\
0\end{array}$ & $\begin{array}{l}E \\
J\end{array}$ \\
\hline & 3 & Dark & 3 & $\begin{array}{l}+ \\
0\end{array}$ & $\begin{array}{l}J \\
E\end{array}$ \\
\hline
\end{tabular}

Pietrzak et al. (2017). At the beginning of each replicate, 200 Daphnia were randomly transferred into two starting containers, each with 100 Daphnia, one with $250 \mathrm{ml}$ of water just taken from the container with the fish and one with $250 \mathrm{ml}$ of water without kairomones. Daphnia were acclimated for $1 \mathrm{~h}$ to the treatment and light conditions. Next, a $225-\mathrm{ml}$ portion of the medium with individuals, captured using a glass pipette ( $4 \mathrm{ml}$ volume, $0.5 \mathrm{~cm}$ diameter) - imitating a predator's attack - was transferred from the starting container to a second container. Transfer was repeated 9 times (from $2^{\text {nd }}$ to $3^{\text {rd }}$, etc., $\ldots$ from $9^{\text {th }}$ to $10^{\text {th }}$ ), leaving $25 \mathrm{ml}$ of the medium in each preceding container and obtaining an equal final volume in all 10 containers. At the end of the experiment, the animals in each container were counted. The main idea was to blindly transfer Daphnia to the next container. Those individuals that were not easy to capture were more evasive and were found mainly in the starting containers at the end of the experiment.

\section{Statistical analysis}

To test the effect of different light sources on RD and SS of juvenile rudd, the Linear Model (LM) was used in R (ver. 3.2.3) with light source as explanatory variable. The effects of the "pair of fish" and "day" were also included in analyses.

The statistical analysis to assess the evasiveness of Daphnia in different treatments was carried out as proposed by Pietrzak et al. (2017). In each treatment and replicate, each of the 100 individuals was designated by the number of the glass container (1-10) in which it was found at the end of the experiment. Then, the GLM analysis (Poisson error distribution, $\log$ link function) followed by the Tukey HSD multiple comparisons test were performed in R (ver. 3.2.3). Decreasing mean number of container (distance travelled) represents increasing evasiveness of an individual (individuals which evaded transfer to successive containers).

\section{Results}

The reaction distance of rudd was significantly lower under the light of HPS than halogen ( $p<0.05$; Fig. 2a). In the case of light produced by the metal halide lamp, RD did not significantly differ with the light produced by the halogen or HPS lamps ( $p>0.05$; Fig. 2a). The model explained 26.52\% of variance, $F(4,32)=2.887$. The swimming speed of fish exposed to HPS light differed significantly from the swimming speed under halogen light $(p<0.05 ;$ Fig. 2b). Between all the other light treatments no significant differences in swimming speed could be observed. ( $p>0.05$; Fig. $2 \mathrm{~b}$ ). The model explained $12.72 \%$ of variance, $\mathrm{F}(4,66)=2.405$. 
Fig. 2 Reaction distance (a) and swimming speed (b) of rudd in three artificial light sources: halogen, HPS and metal halide (asterisk means significant difference at $\alpha=0.05$, LM, $t$ test present in model output, " $n$ " means number of data points) as the mean $( \pm \mathrm{SE})$, and the evasiveness of Daphnia pulex $\times$ pulicaria juveniles in the presence (dark grey) and the absence (light grey) of fish kairomones in three artificial light sources: halogen, HPS and metal halide, and in darkness as a control (c). Evasiveness was measured in relative units, i.e. as the mean $( \pm \mathrm{SE})$ value inversely related to the number of glass containers in which each animal was captured. The shorter the distance they travelled, the higher the evasiveness they represent. Means with the same letter do not significantly differ at $\alpha=0.05$ (Tukey HSD after GLM), the number of data points $(n)$ for each mean is equal $(n=300)$

In both analyses the effect of "pair of fish" and "day" was not significant $(p>0.05)$.

The evasiveness (mean distance travelled) of Daphnia was affected by kairomones (with the exception of the dark treatment) and light source (Tukey HSD test after the GLM analysis, $p<0.05$, Fig. 2c). Individuals showed higher evasiveness (i.e. shorter distance travelled) in halogen light and HPS lights in comparison to the metal halide lamp and darkness (Fig. 2c).

\section{Discussion}

The results of our study revealed that the reaction distance of fish was greater in halogen than in HPS light. Since the spectrum of halogen is the most similar to the spectrum of sunlight compared to other light sources used (Fig. 1a), this result is consistent with the "sensitivity hypothesis", which predicts that the visual system of an animal is suited to natural conditions (Lythgoe 1988; Marshall et al. 2015; Utne-Palm 1999). Our study also revealed that the swimming speed of rudd was greater in halogen than in HPS light. This is consistent with the results obtained in earlier studies, in which the greater swimming speed of fish correlated with better visual conditions (e.g. higher intensity of light), which was attributed to better visibility and greater foraging activity (Batty et al. 1990; Gjelland et al. 2004; Onsrud et al. 2005; Utne-Palm 1999). Two non-exclusive effects could explain the differences in reaction distance and swimming speed between the light sources, both stemming from the fact that halogen lamps emit light at a wider and more continuous spectrum, compared to HPS and metal halide lamps. First, it enables rudd to gain greater visual information by the excitation of more of its photoreceptor classes. Second, it gives greater opportunity to distinguish prey from the background by providing greater visual contrast (Muntz et al. Munz and McFarland 1977). Despite the lower visibility of prey in HPS and metal halide lights compared to halogen light, our study revealed that fish foraging is possible even
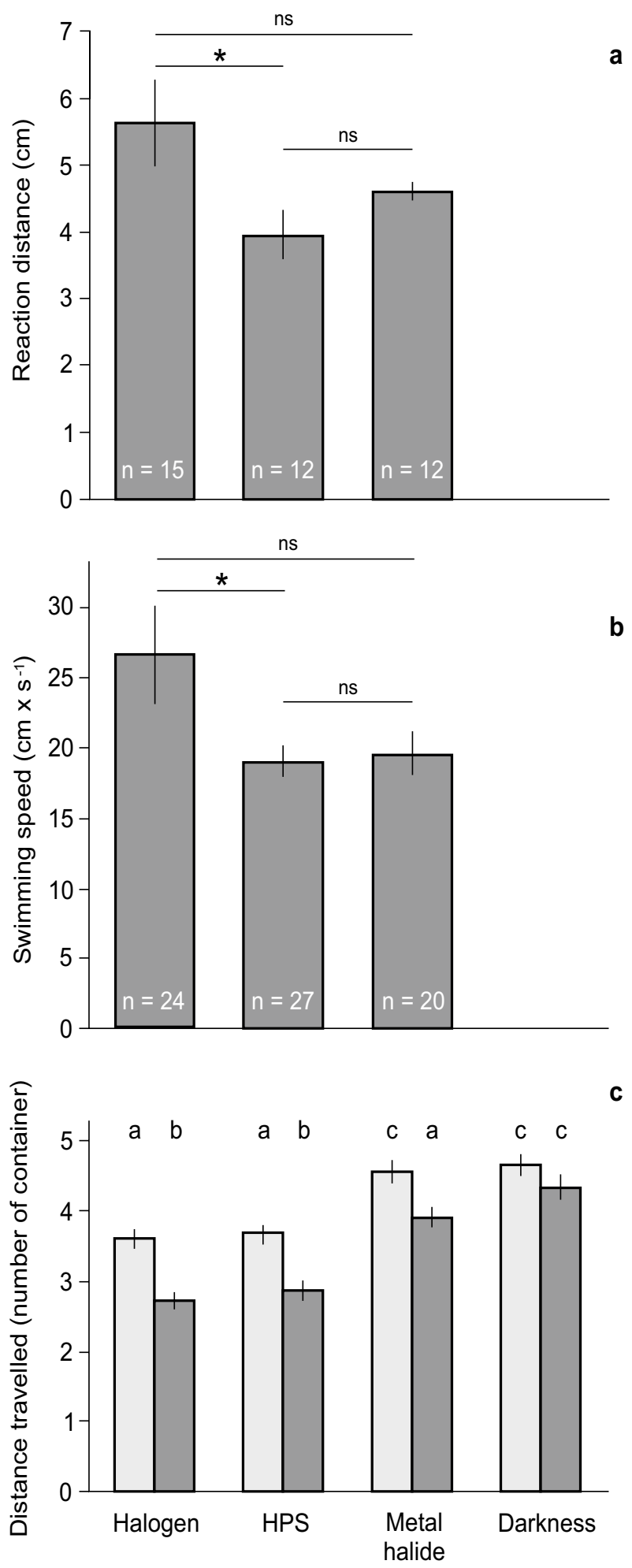

in the very low light intensity of all tested artificial light sources.

The result of the second part of our study showed that Daphnia were less evasive in metal halide lamp light than in any other tested light source. Moreover, their evasiveness 
in the absence of kairomones was similar to that of the darkness treatments, which suggests that Daphnia underestimated predation risk in the light emitted by the metal halide lamp. However, the significant effect of kairomones in metal halide light, but not in darkness, suggests that they perceive and react in this type of light. Nevertheless, evasiveness in the presence of kairomones was still significantly lower in metal halide light than in both halogen and HPS light. This strong reaction in HPS light (comparable to its reaction in halogen light) may be caused by the range of wavelengths at the maximum irradiance of HPS, which is close to the maximum absorbance of the $608 \mathrm{~nm}$ photoreceptor, compared to the fish's $620 \mathrm{~nm}$ photoreceptor. This explanation, however, does not fit the reaction in metal halide light. Thus, it is not possible to decide whether the hypothesis of "the proximity to the range of maximum irradiance" is generally correct, but the discontinuity of the metal halide spectrum is preventing Daphnia from processing and interpretation of the information carried by the light intensity, or whether there is some other factor driving Daphnia's behaviour in artificial light. To test this, additional experiments should be conducted on the physiological sensitivity of the photoreceptors in Daphnia's compound eye under different artificial light sources.

Combining the results from both types of experiments (from the perspectives of the fish and the Daphnia), our study revealed that the evasiveness of Daphnia in halogen light is matched with the predation risk revealed by greater reaction distance and increased swimming speed of planktivorous fish, and suggests that the light spectrum emitted by halogen (as the most similar to sunlight) carries reliable information on the threat of fish predation. Our results also showed a mismatch between Daphnia evasiveness (lower than in other light sources) and the relatively good visual conditions for fish predation in the light of metal halide. This situation may lead to the decreased survival of Daphnia in shallow lakes illuminated by metal halide lamps. The decline of populations of cladocerans that are larger and more visible to fish may influence water quality, as these planktonic animals are filter-feeders which graze on phytoplankton and are able to control algae populations (Dawidowicz et al. 1988; Dawidowicz 1990; Perrow et al. 1994). In consequence, the disruption of this important predator-prey interaction may impact the functioning of the entire lake ecosystem. However, since we performed experiments only with a single Daphnia species and clone, further studies are needed to test interclonal variability of the evasiveness intensity. It would be interesting to check whether the response to these spectra is similar in other behavioural or life history traits. On the other hand, the light of HPS provided the worst visual conditions for juvenile rudd, while daphnids exhibited a similar evasiveness to that revealed in halogen light. However, the consequences of this situation should not be detrimental to the fish. Despite the fact that foraging is then less optimal and more time consuming, fish were still able to forage. Planktivorous fish forage mainly during dusk and dawn due to the low light intensity that hampers the foraging of their predators (antipredation window; Clark and Levy 1988; Hansen and Beauchamp 2015). If the intensity of artificial light is low enough to avoid piscivorous fish (high intensity of artificial light generated by light source from floating restaurant increased activity of large piscivorous fish: Becker et al. 2013), the time of foraging may also be prolonged in this case. Thus, even if the capture rate of the fish is lower in comparison to halogen and metal halide, HPS still enables fish to gain more prey than during naturally dark nights (as the visual predators are almost unable to forage at that time).

In summary, our results show for the first time that some artificial lights affect the outcome of the interaction between planktivorous fish and Daphnia. Eighty-eight per cent of Europe's surface is artificially bright at night (Falchi et al. 2016) and metal halide and HPS lamps are still widely used for outdoor lighting (Elvidge et al. 2010; Kyba et al. 2015), also near the shores of different water bodies. This situation could have a significant effect on the functioning of the entire lake ecosystem and water resource management.

Acknowledgements We would like to thank T. Brzeziński, P. Dawidowicz, J. Pijanowska and two anonymous reviewers for making insightful comments that helped to improve this manuscript, as well as A. Hankiewicz, P. Dynak and I. Sidor for technical support and P. Urban for help with statistics. The study was funded by the Ministry of Science and Higher Education through the Faculty of Biology, University of Warsaw intramural grant DSM 501/86-1126038 to J. Tałanda, supported by National Science Centre grants 2014/13/B/NZ8/04670 to J. Pijanowska and 2014/13/N/NZ8/02462 to P. Maszczyk. Linguistic correction was financed by a National Science Centre grant 2016/21/N/ NZ8/00914 to J. Tałanda. The study was carried out at the Biological and Chemical Research Centre, University of Warsaw, established within a project co-financed by the EU European Regional Development Fund under the 2007-2013 Innovative Economy Operational Programme.

Open Access This article is distributed under the terms of the Creative Commons Attribution 4.0 International License (http://creativeco mmons.org/licenses/by/4.0/), which permits unrestricted use, distribution, and reproduction in any medium, provided you give appropriate credit to the original author(s) and the source, provide a link to the Creative Commons license, and indicate if changes were made.

\section{References}

Bartosiewicz M, Gliwicz ZM (2011) Temporary intermissions in capturing prey (Daphnia) by planktivorous fish (Rutilus rutilus): are they due to scramble competition or the need for antipredation vigilance? Hydrobiologia 668:125-136. https://doi.org/10.1007/ s10750-010-0577-0

Batty RS, Blaxter JHS, Richard JM (1990) Light intensity and the feeding behaviour of herring, Clupea harengus. Mar Biol 107:383388. https://doi.org/10.1007/BF01313419 
Becker A, Whitfield AK, Cowley PD, Järnegren J, Næsje TF (2013) Potential effects of artificial light associated with anthropogenic infrastructure on the abundance and foraging behaviour of estuary-associated fishes. J Appl Ecol 50:43-50. https://doi. org/10.1111/1365-2664.12024

Bowmaker JK (1990) Visual pigments of fishes. In: Douglas R, Djamgoz M (eds) The visual system of fish. Springer, Netherlands, pp 81-107

Brewer MC, Dawidowicz P, Dodson SI (1999) Interactive effects of fish kairomone and light on Daphnia escape behavior. J Plankton Res 21:1317-1335. https://doi.org/10.1093/plankt/21.7.1317

Brüning A, Hölker F, Wolter C (2011) Artificial light at night: implications for early life stages development in four temperate freshwater fish species. Aquat Sci 73:143-152. https://doi.org/10.1007/s0002 7-010-0167-2

Clark CW, Levy DA (1988) Diel vertical migrations by juvenile sockeye salmon and the antipredation window. Am Nat 131:271-290. https://doi.org/10.1086/284789

Dawidowicz P (1990) Effectiveness of phytoplankton control by largebodied and small-bodied zooplankton. In: Lammens EHRR, van Donk E, Meyer M-L (eds) Biomanipulation tool for water management. Springer, Netherlands, pp 43-47

Dawidowicz P, Gliwicz ZM, Gulati RD (1988) Can Daphnia prevent a blue-green algal bloom in hypertrophic lakes? A laboratory test. Limnologica 19:21-26

Downing JEG, Djamgoz MBA, Bowmaker JK (1986) Photoreceptors of a cyprinid fish, the roach: morphological and spectral characteristics. J Comp Physiol A 159:859-868

Drenner RW (1979) Capture probability: the role of zooplankter escape in the selective feeding of planktivorous fish. J Fish Res Board Can 35:1370-1373. https://doi.org/10.1139/f78-215

Effertz C, von Elert E (2014) Light intensity controls anti-predator defences in Daphnia: the suppression of life-history changes. P Roy Soc Lond B Bio 281:20133250. https://doi.org/10.1098/ rspb.2013.3250

Elvidge CD, Keith DM, Tuttle BT, Baugh KE (2010) Spectral identification of lighting type and character. Sensors 10:3961-3988. https://doi.org/10.3390/s100403961

Ervin JL, Haines TA (1972) Using light to collect and separate zooplankton. Progress Fish-Cultur 34:171-174. https://doi. org/10.1577/1548-8640(1972)34[171:ULTCAS]2.0.CO;2

Falchi F, Cinzano P, Duriscoe D, Kyba CC, Elvidge CD, Baugh K, Portnov BA, Rybnikova NA, Furgoni R (2016) The new world atlas of artificial night sky brightness. Sci Adv 2:e1600377. https ://doi.org/10.1126/sciadv.1600377

Gaston KJ, Visser ME, Hölker F (2015) The biological impacts of artificial light at night: the research challenge. Philos T Roy Soc B 370:20140133. https://doi.org/10.1098/rstb.2014.0133

Gjelland KØ, Bøhn T, Knudsen FR, Amundsen PA (2004) Influence of light on the swimming speed of coregonids in subarctic lakes. Ann Zool Fenn 41:137-146

Gliwicz ZM (1986) Predation and the evolution of vertical migration in zooplankton. Nature 320:746-748. https://doi.org/10.1038/32074 $6 \mathrm{a} 0$

Gliwicz ZM, Babkiewicz E, Kumar R, Kunjiappan S, Leniowski K (2017) Warming increases the number of apparent prey in reaction field volume in zooplanktivorous fish. Limnol Oceanogr 63(S1):S30-S43. https://doi.org/10.1002/lno.10720

Greene CH (1983) Selective predation in freshwater zooplankton communities. Int Rev Hydrobio 68:297-315. https://doi.org/10.1002/ iroh.19830680302

Hansen AG, Beauchamp DA (2015) Latitudinal and photic effects on diel foraging and predation risk in freshwater pelagic ecosystems. J Anim Ecol 84:532-544. https://doi.org/10.1111/1365-2656.12295
Hölker F, Wolter C, Perkin EK, Tockner K (2010) Light pollution as a biodiversity threat. Trends Ecol Evol 25:681-682. https://doi. org/10.1016/j.tree.2010.09.007

Hollbach N, Tappeiner C, Jazwinska A, Enzmann V, Tschopp M (2015) Photopic and scotopic spatiotemporal tuning of adult zebrafish vision. Front Syst Neurosci 9:20. https://doi.org/10.3389/fnsys .2015 .00020

Hutchinson GE (1967) A treatise on limnology: introduction to lake biology and the limnoplankton. John Wiley, New York

Ishibashi Y, Honryo T, Saida K, Hagiwara A, Miyashita S, Sawada Y, Okada T, Kurata M (2009) Artificial lighting prevents high night-time mortality of juvenile Pacific bluefin tuna, Thunnus orientalis, caused by poor scotopic vision. Aquaculture 293:157-163. https://doi.org/10.1016/j.aquaculture.2009.04.029

Klüttgen B, Dülmer U, Engels M, Ratte HT (1994) ADaM, an artificial freshwater for the culture of zooplankton. Water Res 28:743-746. https://doi.org/10.1016/0043-1354(94)90157-0

Kyba C, Garz S, Kuechly H, de Miguel AS, Zamorano J, Fischer J, Hölker F (2015) High-resolution imagery of Earth at night: new sources, opportunities and challenges. Remote Sens 7:1-23. https://doi.org/10.3390/rs70100001

Lampert W (2011) Daphnia: development of a model organism in ecology and evolution, vol 21. International Ecology Institute, Oldendorf/Luhe

Lass S, Spaak P (2003) Chemically induced anti-predator defences in plankton: a review. Hydrobiologia 491:221-239. https://doi. org/10.1023/A:1024487804497

Longcore T, Rich C (2004) Ecological light pollution. Front Ecol Environ 2:191-198. https://doi. org/10.1890/1540-9295(2004)002[0191:ELP]2.0.CO;2

Loose CJ, Von Elert E, Dawidowicz P (1993) Chemically induced diel vertical migration in Daphnia: a new bioassay for kairomones exuded by fish. Arch Hydrobiol 126:329-337

Lythgoe JN (1988) Light and vision in the aquatic environment. In: Fay RR, Tavolga WN (eds) Sensory biology of aquatic animals. Springer, New York, pp 57-82

Marshall J, Arikawa K (2014) Unconventional colour vision. Curr Biol 24:50-54. https://doi.org/10.1016/j.cub.2014.10.025

Marshall J, Kent J, Cronin T (1999) Visual adaptations in crustaceans: spectral sensitivity in diverse habitats. In: Archer S, Djamgoz MB, Loew E, Partridge JC, Vallerga S (eds) Adaptive mechanisms in the ecology of vision. Springer, Netherlands, pp 285-327

Marshall J, Carleton KL, Cronin T (2015) Colour vision in marine organisms. Curr Opin Neurobiol 34:86-94. https://doi. org/10.1016/j.conb.2015.02.002

Maszczyk P, Bartosiewicz M (2012) Threat or treat: the role of fish exudates in the growth and life history of Daphnia. Ecosphere 3:1-19. https://doi.org/10.1890/ES12-00146.1

Minnaar C, Boyles JG, Minnaar IA, Sole CL, McKechnie AE (2015) Stacking the odds: light pollution may shift the balance in an ancient predator-prey arms race. J Appl Ecol 52:522-531. https ://doi.org/10.1111/1365-2664.12381

Moore MV, Pierce SM, Walsh HM, Kvalvik SK, Lim JD (2001) Urban light pollution alters the diel vertical migration of Daphnia. Int Ver The 27:779-782

Moore MV, Kohler SJ, Cheers MS (2006) Artificial light at night in freshwater habitats and its potential ecological effects. In: Rich C, Longcore T (eds) Ecological consequences of artificial night lighting. Island Press, Washington, pp 365-384

Munz FW, McFarland WN (1977) Evolutionary adaptations of fishes to the photic environment. In: Crescitelli F (ed) The visual system in vertebrates. Springer, Berlin Heidelberg, pp 193-274

Navara KJ, Nelson RJ (2007) The dark side of light at night: physiological, epidemiological, and ecological consequences. J Pineal Res 43:215-224. https://doi.org/10.1111/j.1600-079X.2007.00473.x 
Onsrud MS, Kaartvedt S, Breien MT (2005) In situ swimming speed and swimming behaviour of fish feeding on the krill Meganyctiphanes norvegica. Can J Fish Aquat Sci 62:1822-1832. https:// doi.org/10.1139/f05-090

Patriarca E, Debernardi P (2010) Bats and light pollution. Centro Regionale Chirotteri, Turin, pp 5-6

Perkin EK, Hölker F, Richardson JS, Sadler J, Wolter C, Tockner K (2011) The influence of artificial light on stream and riparian ecosystems: questions, challenges, and perspectives. Ecosphere 11:1-16. https://doi.org/10.1890/ES11-00241.1

Perkin EK, Hölker F, Tockner K (2014) The effects of artificial lighting on adult aquatic and terrestrial insects. Freshw Biol 59:368-377. https://doi.org/10.1111/fwb.12270

Perrow MR, Moss B, Stansfield J (1994) Trophic interactions in a shallow lake following a reduction in nutrient loading: a long-term study. In: Mortensen E, Jeppsen E, Søndergaard M, Kamp Nielsen L (eds) Nutrient dynamics and biological structure in shallow freshwater and brackish lakes. Springer, Netherlands, pp 43-52

Pietrzak B, Pijanowska J, Dawidowicz P (2017) The effect of temperature and kairomone on Daphnia escape ability: a simple bioassay. Hydrobiologia 798(1):15-23. https://doi.org/10.1007/s1075 0-015-2539-z

Pijanowska J, Dawidowicz P, Weider LJ (2006) Predator-induced escape response in Daphnia. Arch Hydrobiol 167:77-87. https:// doi.org/10.1127/0003-9136/2006/0167-0077

Ringelberg J (1999) The photobehaviour of Daphnia spp. as a model to explain diel vertical migration in zooplankton. Biol Rev 74:397423. https://doi.org/10.1111/j.1469-185X.1999.tb00036.x

Rydell J (2006) Bats and their insect prey at streetlights. In: Rich C, Longcore $\mathrm{T}$ (eds) Ecological consequences of artificial night lighting. Island Press, Washington, pp 43-60

Ślusarczyk M, Dawidowicz P, Rygielska E (2005) Hide, rest or die: a light-mediated diapause response in Daphnia magna to the threat of fish predation. Freshwater Biol. 50:141-146. https://doi.org/10 $.1111 /$ j.1365-2427.2004.01309.x
Smith FE, Baylor ER (1953) Color responses in the Cladocera and their ecological significance. Am Nat 87(832):49-55. https://doi. org/10.1086/281754

Smith KC, Macagno ER (1990) UV photoreceptors in the compound eye of Daphnia magna (Crustacea, Branchiopoda). A fourth spectral class in single ommatidia. J Comp Physiol A 166:597-606. https://doi.org/10.1007/BF00240009

Storz UC, Paul RJ (1998) Phototaxis in water fleas (Daphnia magna) is differently influenced by visible and UV light. J Comp Physiol A 183:709-717. https://doi.org/10.1007/s003590050293

Utne AC (1997) The effect of turbidity and illumination on the reaction distance and search time of the marine planktivore Gobiusculus flavescens. J Fish Biol 50:926-938. https://doi. org/10.1111/j.1095-8649.1997.tb01619.x

Utne-Palm AC (1999) The effect of prey mobility, prey contrast, turbidity and spectral composition on the reaction distance of Gobiusculus flavescens to its planktonic prey. J Fish Biol 54:1244-1258. https://doi.org/10.1111/j.1095-8649.1999.tb02052.x

Van Gool E, Ringelberg J (1995) Swimming of Daphnia galeata $x$ hyalina in response to changing light intensities: influence of food availability and predator kairomone. Mar Freshw Behav Phy 26:259-265. https://doi.org/10.1080/10236249509378944

Vinyard GL, O'Brien WJ (1976) Effects of light and turbidity on the reactive distance of bluegill (Lepomis macrochirus). J Fish Res Board Can 33:2845-2849. https://doi.org/10.1139/f76-342

Weber A, Van Noordwijk A (2002) Swimming behaviour of Daphnia clones: differentiation through predator infochemicals. J Plankton Res 24:1335-1348. https://doi.org/10.1093/plankt/24.12.1335

Whitmore AV, Bowmaker JK (1989) Seasonal variation in cone sensitivity and short-wave absorbing visual pigments in the rudd Scardinius erythrophthalmus. J Comp Physiol A 166:103-115. https ://doi.org/10.1007/BF00190215

Zaret TM (1980) Predation and freshwater communities. Yale Univ. Press, New Haven 